\title{
Osmium(VIII) Catalysed Oxidation of Diclofenac Sodium by Diperiodato- argentate(III) Complex in Aqueous Alkaline Medium
}

\author{
Roopa H. Patil, Praveen N. Naik and Sharanappa T. Nandibewoor* \\ P.G. Department of Studies in Chemistry, Karnatak University, Dharwad 580003, India
}

\begin{abstract}
The kinetics of Osmium(VIII) (Os(VIII)) catalysed oxidation of diclofenac sodium (DFS) by diperiodatoargentate(III) (DPA) in alkaline medium at a constant ionic strength of $0.60 \mathrm{~mol} \mathrm{dm}^{-3}$ has been studied spectrophotometrically. The stoichiometry was found to be 1:1 i.e, one mole of DFS reacted with one mole of DPA. The reaction was first order with respect to [DPA] and [Os(VIII)], less than unit order in both [DFS] and [alkali] and negative fractional order in [periodate]. The effect of added products, ionic strength and dielectric constant of the medium was studied. The oxidation reaction in alkaline medium has been shown to proceed via a Os(VIII)-DFS complex, which further reacts with one molecule of monoperiodatoargentate in a rate determining step followed by other fast steps to give the products. The oxidation products were identified by LC-ESI-MS, NMR and IR spectral studies. The reaction constants involved in different steps of the mechanism were calculated. The activation parameters with respect to slow step of the mechanism were computed and discussed and thermodynamic quantities were also determined. The catalytic constant $\left(\mathrm{K}_{\mathrm{c}}\right)$ was also calculated for Os(VIII) catalysis at different temperatures and values of activation parameters with respect to the catalyst have been evaluated. The active species of catalyst and oxidant have been identified.
\end{abstract}

Keywords: Kinetics, oxidation, diclofenac sodium, diperiodatoargentate(III), Os(VIII) catalysis.

\section{INTRODUCTION}

Diperiodatoargentate(III) (DPA) is a powerful oxidising agent in alkaline medium with reduction potential [1] 1.74 V. It is widely used as a volumetric reagent for the determination of various organic and inorganic species [2]. Jayaprakash Rao et al. [3] have used DPA as an oxidising agent for the kinetics of oxidation of various organic substrates. They normally found that order with respect to both oxidant and substrate was unity and $\left[\mathrm{OH}^{-}\right]$was found to enhance the rate of reaction. It was also observed that they did not arrive the possible active species of DPA in alkali and on the other hand they proposed mechanisms by generalising the DPA as $[\mathrm{Ag}(\mathrm{HL}) \mathrm{L}]^{(\mathrm{x}+1) \text { - }}$. However, Kumar et al. [4] put an effort to give an evidence for the reactive form of DPA in the large scale of alkaline $\mathrm{pH}$. In the present investigation, we have obtained the evidence for the reactive species for DPA in alkaline medium.

Diclofenac, [o-(2,6-dichlorophenyl)amino]phenyl] acetic acid (DFS) belongs to a class of drugs called nonsteroidal anti-inflammatory drugs (NSAIDs). In pharmacological studies, diclofenac has shown anti-inflammatory, analgesic and antipyretic activity [5]. As with other NSAIDs, its mode of action is not known; its ability to inhibit prostaglandin synthesis, however, may be involved in its anti-inflammatory activity, as well as contributing to its efficiency in relieving pain related to inflammation and primary dysmenorrhea. Diclofenac is used in treating osteoarthritis, rheumatoid arthritis and ankylosing spondylitis [6]. Due to its low solubility, it is commercially available as its sodium salt.

*Address correspondence to this author at the P.G. Department of Studies in Chemistry, Karnatak University, Dharwad 580003, India; Fax: 91-836274788; E-mail: stnandibewoor@yahoo.com
In recent years, the use of transition metal ions such as osmium, ruthenium and iridium, either alone or as binary mixtures, as catalysts in various redox processes has attracted considerable interest [7]. The role of osmium(VIII) as a catalyst in some redox reactions has been reviewed [8]. Although the mechanism of catalysis depends on the nature of the substrate, the oxidant and experimental conditions, it has been shown [9] that metal ions act as catalysts by one of these different paths such as the formation of complexes with reactants or oxidation of the substrate itself or through the formation of free radicals.

Osmium(VIII) catalysis in redox reactions involves different degrees of complexity, due to the formation of different intermediate complexes and different oxidation states of osmium. The uncatalysed reaction of oxidation of DFS by DPA has been studied [10]. We have observed that osmium(VIII) catalyses the oxidation of DFS by DPA in alkaline medium in micro amounts.

So far there is no report on the kinetics of Os(VIII) catalysed oxidation of DFS by DPA. In view of potential pharmaceutical importance of DFS, the active species of $\mathrm{Ag}(\mathrm{III})$, osmium(VIII) and the complexity of the reaction, a detailed study of the reaction becomes important. The present investigation is aimed at checking the reactivity of DFS towards DPA in osmium(VIII) catalysed reaction and to understand the active species of oxidant and catalyst. Further we have isolated the oxidized products in a way to arrive at a suitable mechanism on the basis of kinetic and spectral results and to compute the thermodynamic quantities of various steps. An understanding of the mechanism allows the chemistry to be interpreted, understood and predicted. 


\section{EXPERIMENTAL}

\subsection{Materials and Reagents}

All reagents were of reagent grade and millipore water was used throughout the work. A solution of DFS (IP) was prepared by dissolving an appropriate amount of recrystallised sample in millipore water. The purity of DFS concentration was checked by potentiometrically. The IR spectrum of DFS agreed with that of literature. The required concentration of DFS was used from its stock solution. A standard stock solution of Os(VIII) was prepared by dissolving $\mathrm{OsO}_{4}$ oxide (Johnson Matthey) in $0.50 \mathrm{~mol} \mathrm{dm}^{-3}$ $\mathrm{NaOH}$. The concentration was ascertained [11] by determining the unreacted $\left[\mathrm{Fe}(\mathrm{CN})_{6}\right]^{4-}$ with standard $\mathrm{Ce}(\mathrm{IV})$ solution in an acidic medium. The ionic strength and alkalinity of the reaction were maintained by $\mathrm{KNO}_{3}$ and $\mathrm{KOH}(\mathrm{BDH})$ respectively. An aqueous solution of $\mathrm{AgNO}_{3}$ was used to study the product effect, $\operatorname{Ag}(\mathrm{I})$. A stock solution of $\mathrm{IO}_{4}{ }^{-}$was prepared by dissolving a known weight of $\mathrm{KIO}_{4}$ (Riedel-de-Haen) in hot water and used after keeping for $24 \mathrm{~h}$. Its concentration was ascertained iodometrically [12], at neutral $\mathrm{pH}$ maintained using phosphate buffer.

\subsection{Preparation of DPA}

DPA was prepared by oxidising $\operatorname{Ag}(\mathrm{I})$ in presence of $\mathrm{KIO}_{4}$ as described elsewhere [13]. The complex was characterized from its UV spectrum, which exhibited three peaks at 216, 255 and $362 \mathrm{~nm}$. These spectral features were identical to those reported earlier for DPA [13]. The magnetic moment study revealed that the complex is diamagnetic. The compound prepared was analysed [14] for silver and periodate by acidifying a solution of the material with $\mathrm{HCl}$, recovering and weighing the $\mathrm{AgCl}$ for $\mathrm{Ag}$ and titrating the iodine liberated when excess KI was added to the filtrate for $\mathrm{IO}_{4}^{-}$. The aqueous solution of DPA was used for the required [DPA] in the reaction mixture.

\subsection{Instruments Used}

A) For kinetics measurements, CARY 50 Bio UV-vis Spectrophotometer (Varian, Victoria-3170, Australia) was used.

B) For product analysis, an LC-ESI-MS (HewlettPackard GmbH, Waldbronn, Germany), Nicolet 5700 - FT-IR spectrometer (Thermo, U.S.A.) and 300 $\mathrm{MHz}{ }^{1} \mathrm{H}$ NMR spectrometer (Bruker, Switzerland) were used.

C) The $\mathrm{pH}$ of the medium in the solution was measured by [ELICO (L1613)] pH meter.

\subsection{Kinetic Measurements}

The kinetics of Os(VIII) catalysed oxidation of DFS by DPA was followed under pseudo first order condition where [DFS] $>$ [DPA] catalysed reaction at $298 \mathrm{~K}$, unless specified. The reaction in the presence of catalyst was initiated by mixing DFS to DPA solution which also contained the required concentration of $\mathrm{KNO}_{3}, \mathrm{KOH}, \mathrm{Os}(\mathrm{VIII})$ catalyst and $\mathrm{KIO}_{4}$. The progress of the reaction was monitored spectrophotometrically at $360 \mathrm{~nm}$ (i.e., decrease in absorbance due to DPA with the molar absorbancy index, ' $\varepsilon$ ' to be $13,900 \pm 100 \mathrm{dm}^{3} \mathrm{~mol}^{-1} \mathrm{~cm}^{-1}$ ), which is the maximum absorption wavelength of DPA. The spectral changes during the reaction infer that the concentration of DPA decreases at $360 \mathrm{~nm}$. It was verified that there was almost no interference from other species in the reaction mixture at this wavelength.

The pseudo-first order rate constants, ' $\mathrm{k}_{\mathrm{c}}$ ' were determined from the log (absorbance) vs time plots. The plots were linear up to $80 \%$ completion of reaction under the range of $\left[\mathrm{OH}^{-}\right]$used. The orders for various species were determined from the slopes of plots of $\log \mathrm{k}_{\mathrm{c}} v s$ respective concentration of species except for [DPA] in which nonvariation of ' $k_{\mathrm{c}}$ ' was observed as expected to the reaction condition. During the kinetics a constant concentration, viz. $1.0 \times 10^{-5} \mathrm{~mol} \mathrm{dm}^{-3}$ of $\mathrm{KIO}_{4}$ was used throughout the study unless otherwise stated. Since periodate is present in the excess in DPA, the possibility of oxidation of DFS by periodate in alkaline medium at $298 \mathrm{~K}$ was tested. The progress of the reaction was followed iodometrically. However, it was found that there was no significant reaction under the experimental conditions employed compared to the DPA oxidation of DFS. The total concentrations of periodate and alkali was calculated by considering the amount present in the DPA solution and that additionally added. Dissolved $\mathrm{O}_{2}, \mathrm{CO}_{2}$ and surface of reaction vessel had no effect on the reaction rate. Fresh solutions were used for carrying out each kinetic study.

\section{RESULTS}

\subsection{Stoichiometry and Product Analysis}

Different sets of reaction mixtures containing varying ratios of DPA to DFS in presence of constant amount of $\mathrm{OH}^{-}$ , $\mathrm{KIO}_{4}, \mathrm{KNO}_{3}$, and $\mathrm{Os}(\mathrm{VIII})$ were kept for $4 \mathrm{hrs}$ in a closed vessel under nitrogen atmosphere. The remaining concentration of DPA was assayed by measuring the absorbance at $360 \mathrm{~nm}$. The results indicated that one mole of DFS reacted with one mole of DPA, as given in Scheme 1.

The oxidation product of DFS, [2-(2, 6-dichlorophenylamino)-phenyl]-methanol was isolated with the help of preparative TLC and other separation technique and characterized by LC-ESI-MS, FTIR and ${ }^{1} \mathrm{H}-\mathrm{NMR}$ spectral studies.

LC-ESI-MS analysis was carried out using reverse phase high performance liquid chromatography (HPLC) system with a phenomenon C-18 column, UV/Visible detector and series mass analyzer. $12 \mu \mathrm{L}$ of acidified reaction mixture was injected. The mobile phase consisted of $10 \mathrm{mM}$ ammonium acetate $\mathrm{pH} 3.0$ (eluent $\mathrm{A}$ ) and acetic acid(eluent B) at a flow rate of $1 \mathrm{ml} / \mathrm{min}$. Gradient elution was run to separate the substrate and reaction products. LC-ESI-MS analysis indicated the presence of two main products with molecular ions of $\mathrm{m} / \mathrm{z}$ at 273(Yield ca $90 \%$ ) and 598(Yield ca 5\%) respectively (Fig. 1). The molecular ion of DFS is $\mathrm{m} / \mathrm{z} 299$. The $\mathrm{m} / \mathrm{z}$ at 598 corresponds to dimer product of DFS. The product [2-(2, 6-dichloro-phenylamino)-phenyl]-methanol is further confirmed by its characteristic IR and ${ }^{1} \mathrm{H}$ NMR spectrum. The disappearance of the sharp band (peak) at $1695 \mathrm{~cm}^{-1}$ due to acidic carbonyl in DFS confirms the product. Further secondary amine (-NH) group observed around $3387 \mathrm{~cm}^{-1}$ in DFS, remains in the product (Fig. 2). In ${ }^{1} \mathrm{H}-\mathrm{NMR}$ (DMSO) spectrum shows, the disappearance of the acidic -OH band of DFS and appearance of alcoholic 
hydroxyl proton triplet band at $6.859 \mathrm{ppm}$ confirms the product. Further secondary amine(-NH) proton singlet band around $3.69 \mathrm{ppm}$ and other aromatic proton bands in DFS remains in the product, which disappears on $\mathrm{D}_{2} \mathrm{O}$ exchange confirms the formation of product [2-(2, 6-dichlorophenylamino)-phenyl]-methanol (Fig. 3). All these observations proved the formation of [2-(2, 6-dichloro-phenylamino)phenyl]-methanol as a major product. The formation of free $\mathrm{Ag}^{+}$in solution was detected by adding $\mathrm{KCl}$ solution to the reaction mixture, which produced white turbidity due to the formation of $\mathrm{AgCl}$. The dimer structure of DFS is

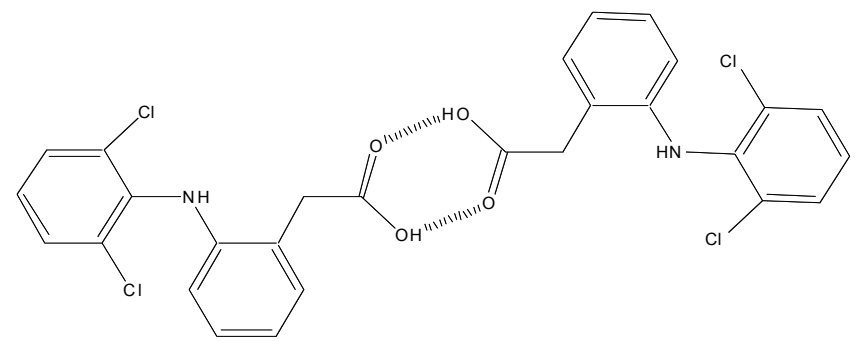

Regression analysis of experimental data to obtain the regression coefficient $\mathrm{r}$ and standard deviation $\mathrm{S}$, of points from the regression line was performed using Microsoft Excel-2003 programme.

\subsection{Reaction Orders}

As the diperiodatoargentate(III) oxidation of DFS in alkaline medium proceeds with a measurable rate in the absence of Os(VIII), the catalysed reaction is understood to occur in parallel paths with contributions from both the catalysed and uncatalysed paths. Thus the total rate constant $\left(\mathrm{k}_{\mathrm{T}}\right)$ is equal to the sum of the rate constants of the catalysed $\left(\mathrm{k}_{\mathrm{C}}\right)$ and uncatalysed $\left(\mathrm{k}_{\mathrm{U}}\right)$ reactions, so $\mathrm{k}_{\mathrm{C}}=\mathrm{k}_{\mathrm{T}}-\mathrm{k}_{\mathrm{U}}$. Hence the reaction orders have been determined from the slopes of $\log \mathrm{k}_{\mathrm{C}}$ versus $\log$ (concentration) plots by varying the concentrations of DFS, $\mathrm{IO}_{4}^{-}, \mathrm{OH}^{-}$and $\mathrm{Os}(\mathrm{VIII})$, in turn while keeping others constant. The DPA concentration was varied in the range of $1.0 \times 10^{-5}$ to $1.0 \times 10^{-4} \mathrm{~mol} \mathrm{dm}^{-3}$ and the linearity of the plots of $\log$ (absorbance) $v s$ time up to $80 \%$ completion of reaction indicates a reaction order unity in [DPA] (Fig. 4). This is also confirmed by varying of [DPA], which did not result in any change in the pseudo first-order rate constants, $\mathrm{k}_{\mathrm{C}}$ (Table 1). The substrate DFS was varied in the range of $1.0 \times 10^{-4}$ to $1.0 \times 10^{-3} \mathrm{~mol} \mathrm{dm}^{-3}$ at $298 \mathrm{~K}$ while keeping other reactant concentration and condition constant. The $\mathrm{k}_{\mathrm{C}}$ values increased with increase in concentration of DFS indicating an apparent less than unit order dependence on [DFS] (Table 1). The effect of alkali on the reaction has been studied in the range of 0.05 to $0.50 \mathrm{~mol} \mathrm{dm}^{-3}$ at constant concentrations of DFS, DPA, Os(VIII), $\mathrm{IO}_{4}{ }^{-}$and a constant
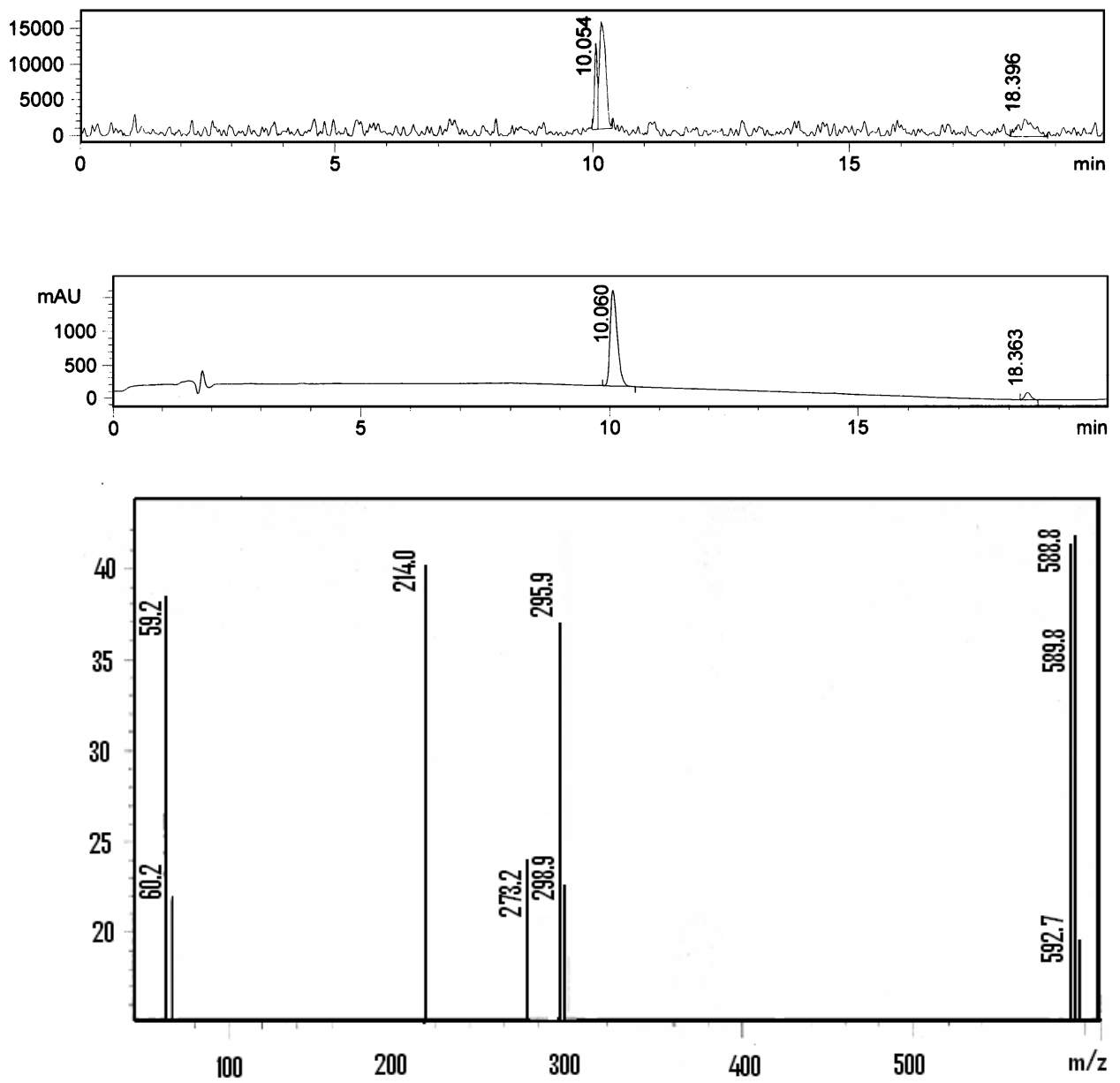

Fig. (1). Chromatogram \& LC - ESI - MS spectra of the product of Os(VIII) catalysed oxidation of diclofenac sodium by diperiodatoargantate (III) in aqueous alkaline medium. 


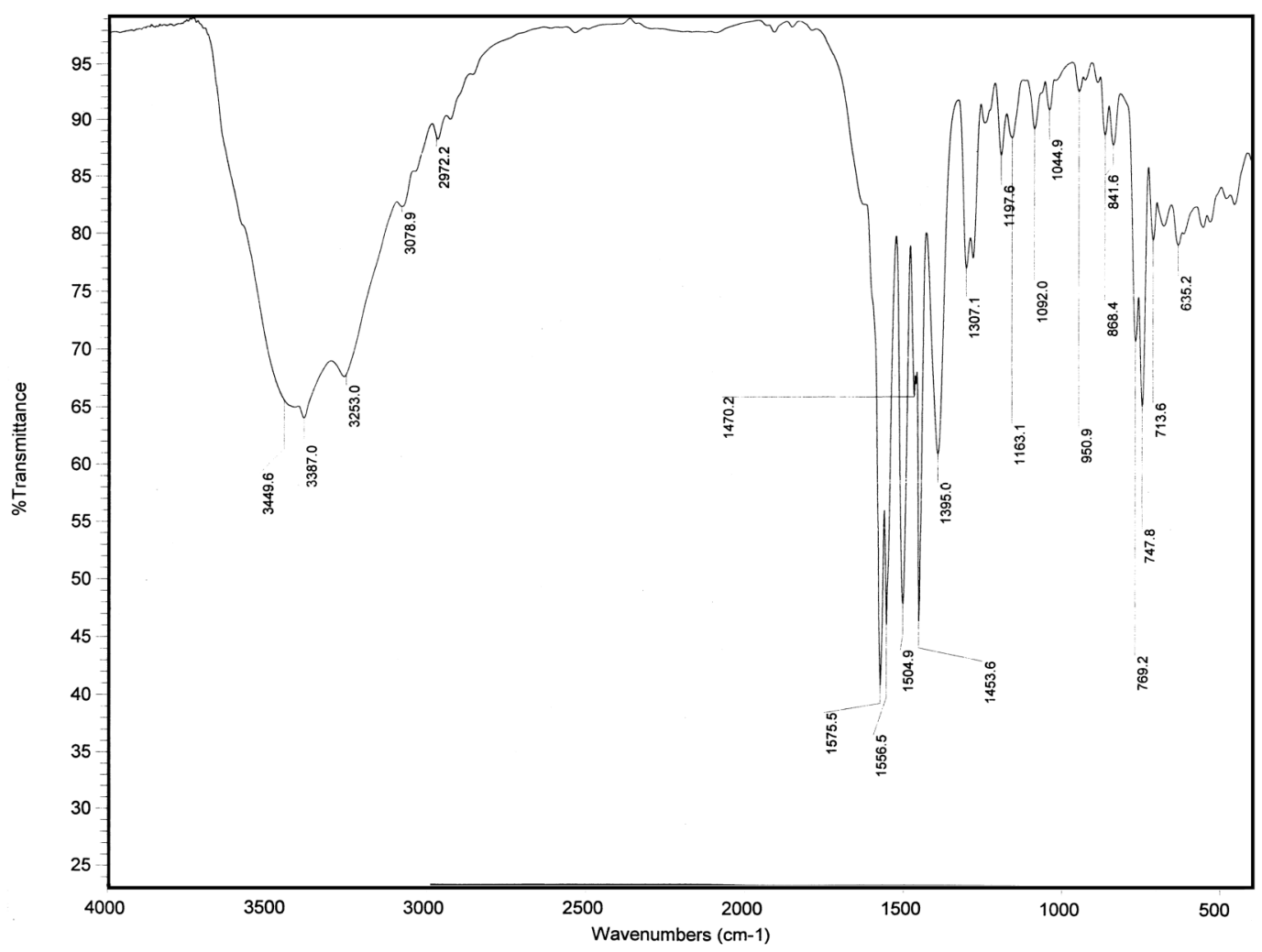

Fig. (2). FT-IR spectra of the product of Os(VIII) catalysed of oxidation of diclofenac sodium by diperiodatoargantate (III) in aqueous alkaline medium.

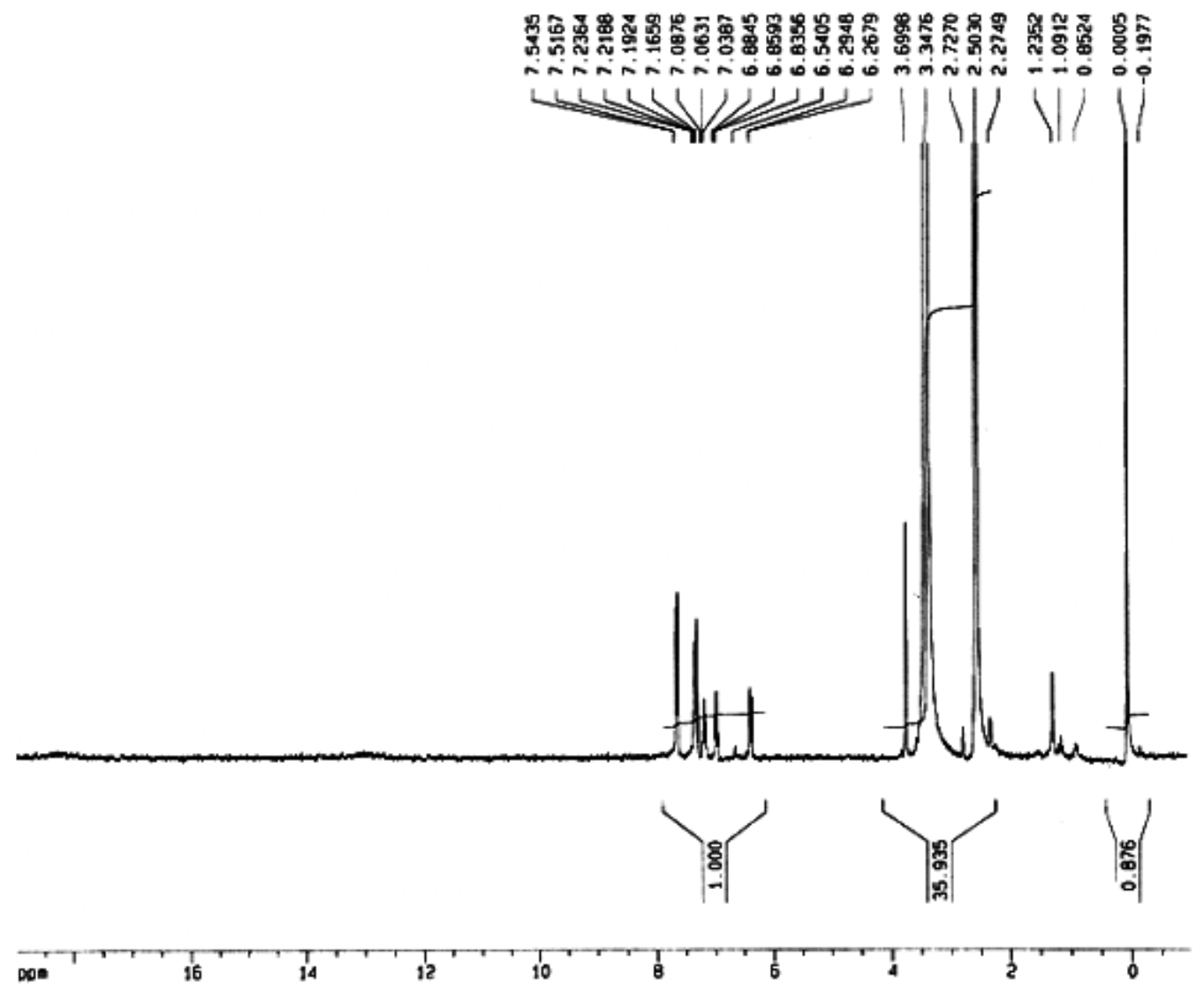

Fig. (3). ${ }^{1} \mathrm{H}-\mathrm{NMR}$ spectra of the product of Os(VIII) catalysed oxidation of diclofenac sodium by diperiodatoargantate (III)in aqueous alkaline medium. 


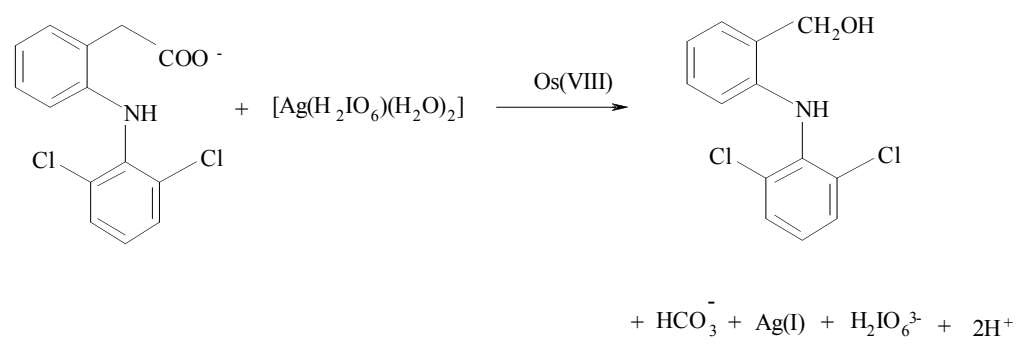

Scheme 1. 1:1 stoichiometry.

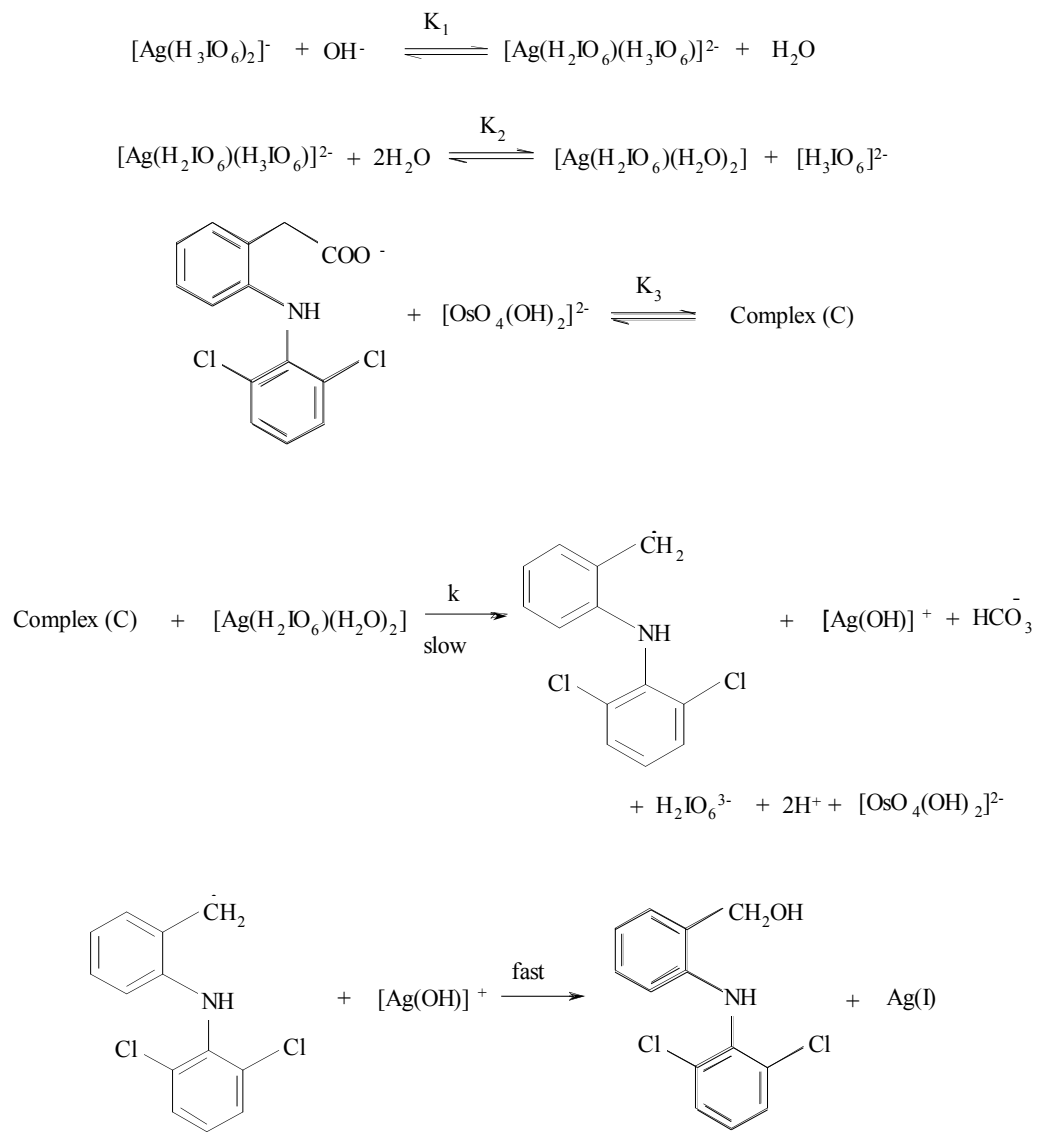

Scheme 2. Detailed Scheme for the oxidation of osmium(VIII) catalysed oxidation of DFS by diperiodatoargentate(III) in aqueous alkaline medium.

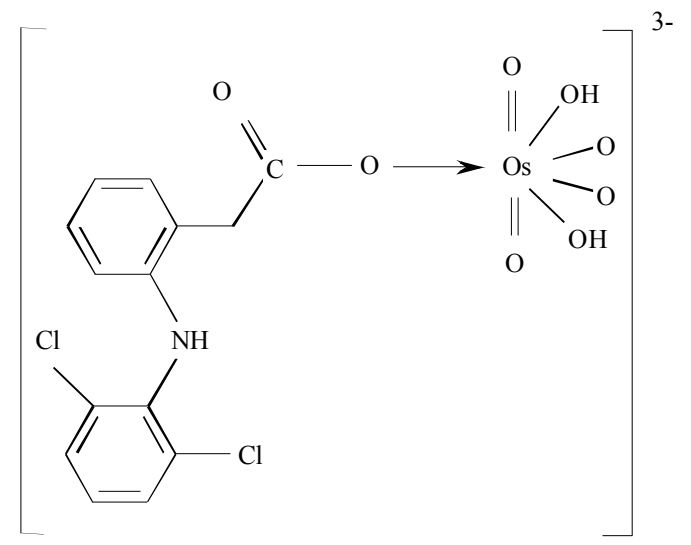

Scheme 3. The probable structure of the osmium(VIII) and DFS complex.

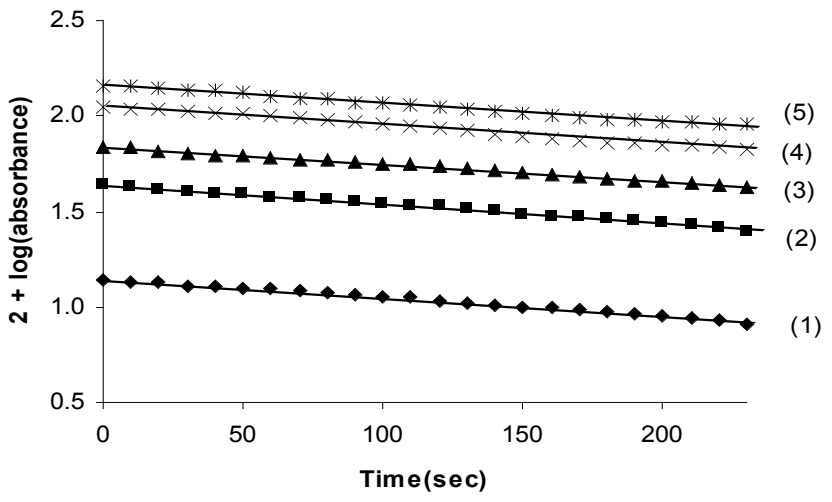

Fig. (4). First order plots on the Os(VIII) catalysed oxidation of diclofenac sodium by diperiodatoargantate (III) in aqueous alkaline medium at $25^{0} \mathrm{C}$. [DPA] $\left.\times 10^{5} \mathrm{~mol} \mathrm{dm}^{-3}: 1\right) 1.0$ 2)3.0 3) 5.04 ) 8.0 5) 10.0. 


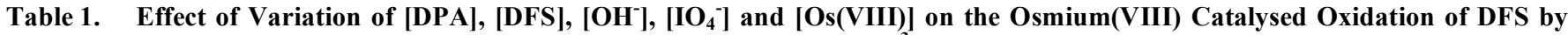
DPA in Aqueous Alkaline Medium at $298 \mathrm{~K}$ and $\mathrm{I}=0.60 \mathrm{~mol} \mathrm{dm}^{-3}$

\begin{tabular}{|c|c|c|c|c|c|c|c|c|}
\hline \multirow{2}{*}{$\begin{array}{l}{[\mathrm{DPA}] \times \mathbf{x 1 0}^{5}} \\
\left(\mathrm{~mol} \mathrm{dm}^{-3}\right)\end{array}$} & \multirow{2}{*}{$\begin{array}{l}{[\mathrm{DFS}] \times \mathbf{x 1 0}^{4}} \\
\left(\mathrm{~mol} \mathrm{dm}^{-3}\right)\end{array}$} & \multirow{2}{*}{$\frac{\left[\mathrm{OH}^{-}\right]}{\left(\mathrm{mol} \mathrm{dm}^{-3}\right)}$} & \multirow{2}{*}{$\begin{array}{l}{\left[\mathrm{IO}_{4}^{-}\right] \times 10^{5}} \\
\left(\mathrm{~mol} \mathrm{dm}^{-3}\right)\end{array}$} & \multirow{2}{*}{$\begin{array}{l}{[\mathrm{Os}(\mathrm{VIII})] \times \mathrm{x10}^{6}} \\
\left(\mathrm{~mol} \mathrm{dm}^{-3}\right)\end{array}$} & \multirow{2}{*}{$\begin{array}{c}\mathbf{k}_{\mathrm{T}} \mathbf{x 1 0 ^ { 3 }} \\
\left(\mathrm{s}^{-1}\right)\end{array}$} & \multirow{2}{*}{$\begin{array}{c}\mathbf{k}_{\mathrm{U}} \times 10^{4} \\
\left(\mathrm{~s}^{-1}\right)\end{array}$} & \multicolumn{2}{|c|}{$k_{C} \times 10^{3}\left(s^{-1}\right)$} \\
\hline & & & & & & & Found & Calculated \\
\hline 1.0 & 5.0 & 0.5 & 1.0 & 8.0 & 2.36 & 7.30 & 1.63 & 1.63 \\
\hline 3.0 & 5.0 & 0.5 & 1.0 & 8.0 & 2.35 & 7.16 & 1.63 & 1.63 \\
\hline 5.0 & 5.0 & 0.5 & 1.0 & 8.0 & 2.34 & 7.38 & 1.60 & 1.63 \\
\hline 8.0 & 5.0 & 0.5 & 1.0 & 8.0 & 2.35 & 7.14 & 1.64 & 1.63 \\
\hline 10.0 & 5.0 & 0.5 & 1.0 & 8.0 & 2.33 & 7.20 & 1.61 & 1.63 \\
\hline 5.0 & 1.0 & 0.5 & 1.0 & 8.0 & 0.69 & 2.21 & 0.47 & 0.47 \\
\hline 5.0 & 3.0 & 0.5 & 1.0 & 8.0 & 1.63 & 5.30 & 1.10 & 1.16 \\
\hline 5.0 & 5.0 & 0.5 & 1.0 & 8.0 & 2.42 & 7.38 & 1.68 & 1.63 \\
\hline 5.0 & 8.0 & 0.5 & 1.0 & 8.0 & 2.95 & 8.81 & 2.07 & 2.12 \\
\hline 5.0 & 10.0 & 0.5 & 1.0 & 8.0 & 3.40 & 9.80 & 2.42 & 2.35 \\
\hline 5.0 & 5.0 & 0.05 & 1.0 & 8.0 & 0.64 & 1.88 & 0.45 & 0.45 \\
\hline 5.0 & 5.0 & 0.08 & 1.0 & 8.0 & 0.91 & 2.56 & 0.65 & 0.65 \\
\hline 5.0 & 5.0 & 0.1 & 1.0 & 8.0 & 1.08 & 3.21 & 0.76 & 0.76 \\
\hline 5.0 & 5.0 & 0.3 & 1.0 & 8.0 & 1.92 & 6.07 & 1.31 & 1.37 \\
\hline 5.0 & 5.0 & 0.5 & 1.0 & 8.0 & 2.42 & 7.38 & 1.68 & 1.63 \\
\hline 5.0 & 5.0 & 0.5 & 1.0 & 8.0 & 2.42 & 7.38 & 1.68 & 1.63 \\
\hline 5.0 & 5.0 & 0.5 & 3.0 & 8.0 & 1.45 & 4.25 & 1.02 & 1.00 \\
\hline 5.0 & 5.0 & 0.5 & 5.0 & 8.0 & 1.02 & 2.99 & 0.72 & 0.72 \\
\hline 5.0 & 5.0 & 0.5 & 8.0 & 8.0 & 0.72 & 2.06 & 0.51 & 0.51 \\
\hline 5.0 & 5.0 & 0.5 & 10.0 & 8.0 & 0.61 & 1.71 & 0.44 & 0.42 \\
\hline 5.0 & 5.0 & 0.5 & 1.0 & 4.0 & 1.54 & 7.38 & 0.80 & 0.81 \\
\hline 5.0 & 5.0 & 0.5 & 1.0 & 8.0 & 2.40 & 7.38 & 1.66 & 1.63 \\
\hline 5.0 & 5.0 & 0.5 & 1.0 & 10.0 & 2.83 & 7.38 & 2.09 & 2.04 \\
\hline 5.0 & 5.0 & 0.5 & 1.0 & 20.0 & 4.98 & 7.38 & 4.24 & 4.08 \\
\hline 5.0 & 5.0 & 0.5 & 1.0 & 40.0 & 9.28 & 7.38 & 8.54 & 8.16 \\
\hline
\end{tabular}

ionic strength of $0.60 \mathrm{~mol} \mathrm{dm} \mathrm{dm}^{-3}$. The rate constants increased with increasing [alkali] and the order was found to be less than unity (Table 1).

\subsection{Effect of [Periodate]}

Periodate concentration was varied from $1.0 \times 10^{-5}$ to 1.0 $\mathrm{x} 10^{-4} \mathrm{~mol} \mathrm{dm}^{-3}$ at constant [DPA], [DFS], [Os(VIII)] and ionic strength. It was observed that the rate constants decreased by increasing $\left[\mathrm{IO}_{4}^{-}\right]$(Table $\mathbf{1}$ ).

\subsection{Effect of Added Products}

The effect of initially added products, [2-(2,6dichlorophenylamino)-phenyl]-methanol and $\mathrm{Ag}(\mathrm{I})\left(\mathrm{AgNO}_{3}\right)$ did not have any significant effect on the rate of the reaction.

\subsection{Effect of Ionic Strength and Dielectric Constant}

The ionic strength (addition of $\mathrm{KNO}_{3}$ ) and dielectric constant(t-butyl alcohol-water \%) of the medium had no significant effect on the rate of reaction.

\subsection{Test for Free Radicals (Polymerization Study)}

The intervention of free radicals in the reaction was examined as follows. The reaction mixture, to which a known quantity of acrylonitrile monomer was initially added, was kept for 2 hrs in an inert atmosphere. On diluting the reaction mixture with methanol, white precipitate was formed, indicating the intervention of free radicals in the reaction. The blank experiments of either DPA or DFS alone with acrylonitrile did not induce any polymerization under the same condition as those induced for reaction mixture. Initially added acrylonitrile decreases the rate of reaction indicating free radical intervention, which is the case in earlier work [15].

\subsection{Effect of Temperature (T)}

The influence of temperature on the rate of reaction was studied at 293, 298, 303 and $313 \mathrm{~K}$. The rate constants (k), of the slow step of Scheme 2 were obtained from the slopes and the intercepts of the plots of [Os(VIII)] $/ \mathrm{k}_{\mathrm{C}}$ vs $1 /[\mathrm{DFS}]$ plot at four different temperatures. The values are given in Table 2. The activation parameters for the rate determining step were obtained by the least square method of plot of log $\mathrm{k}$ versus $1 / \mathrm{T}$ and are presented in Table 2 .

\subsection{Effect of [Os(VIII)]}

The $[\mathrm{Os}(\mathrm{VIII})]$ concentrations was varied from $4.0 \times 10^{-6}$ to $4.0 \times 10^{-5} \mathrm{~mol} \mathrm{dm}^{-3}$ range, at constant concentration of DPA, DFS, alkali and ionic strength. The order in [Os(VIII)] was found to be unity.

\subsection{Catalytic Activity}

It has been pointed out by Moelwyn-Hughes [16] that in the presence of catalyst, the uncatalysed and catalysed reactions proceed simultaneously, so that, 
$\mathrm{k}_{\mathrm{T}}=\mathrm{k}_{\mathrm{U}}+\mathrm{K}_{\mathrm{C}}$ [catalyst $]^{\mathrm{x}}$

Table 2. Activation Parameters and Thermodynamic Quantities for the Osmium(VIII) Catalysed Oxidation of DFS by DPA in Aqueous Alkaline Medium with Respect to the Slow Step of Scheme 2

(a) Effect of Temperature

\begin{tabular}{|c|c|}
\hline Temperature (K) & $\mathbf{k ~ x ~} \mathbf{1 0}^{-\mathbf{2}}\left(\mathbf{d m}^{\mathbf{3}} \mathbf{~ m o l}^{-1} \mathbf{s}^{-1}\right)$ \\
\hline \hline 293 & 4.19 \\
\hline 298 & 5.28 \\
\hline 303 & 6.36 \\
\hline 313 & 8.51 \\
\hline
\end{tabular}

(b) Activation Parameters

\begin{tabular}{|c|c|}
\hline Parameter & Value \\
\hline \hline $\mathrm{E}_{\mathrm{a}}\left(\mathrm{kJ} \mathrm{mol}^{-1}\right)$ & $26.7 \pm 1.2$ \\
\hline$\Delta \mathrm{H}^{\#}\left(\mathrm{~kJ} \mathrm{~mol}^{-1}\right)$ & $24.2 \pm 1.2$ \\
\hline$\Delta \mathrm{S}^{\#}\left(\mathrm{JK}^{-1} \mathrm{~mol}^{-1}\right)$ & $-111 \pm 5$ \\
\hline$\Delta \mathrm{G}^{\#}\left(\mathrm{~kJ} \mathrm{~mol}^{-1}\right)$ & $57.4 \pm 2.8$ \\
\hline $\log \mathrm{A}$ & $7.4 \pm 0.3$ \\
\hline
\end{tabular}

(c) Effect of Temperature on $K_{1}, K_{2}$ and $K_{3}$ for the Osmium(VIII) Catalysed Oxidation of DFS by DPA in Aqueous Alkaline Medium

\begin{tabular}{|c|c|c|c|}
\hline Temperature (K) & $\begin{array}{c}\mathbf{K}_{\mathbf{1}} \\
\left(\mathbf{d m}^{\mathbf{3}} \mathbf{~ m o l}^{-\mathbf{1}} \mathbf{)}\right.\end{array}$ & $\begin{array}{c}\mathbf{K}_{\mathbf{2}} \mathbf{x} \mathbf{1 0}^{\mathbf{4}} \\
\left(\mathbf{m o l ~ d m}^{-3}\right)\end{array}$ & $\begin{array}{c}\mathbf{K}_{\mathbf{3}} \mathbf{x} \mathbf{1 0}^{-3} \\
\left(\mathbf{d m}^{\mathbf{3}} \mathbf{~ m o l}^{-\mathbf{1}} \mathbf{)}\right.\end{array}$ \\
\hline \hline 293 & $0.13 \pm 0.006$ & $1.67 \pm 0.08$ & $1.88 \pm 0.09$ \\
\hline 298 & $0.20 \pm 0.008$ & $1.03 \pm 0.05$ & $2.60 \pm 0.12$ \\
\hline 303 & $0.27 \pm 0.01$ & $0.61 \pm 0.03$ & $3.23 \pm 0.16$ \\
\hline 313 & $0.50 \pm 0.02$ & $0.24 \pm 0.01$ & $6.63 \pm 0.32$ \\
\hline
\end{tabular}

(d) Thermodynamic Quantities Using $K_{1}, K_{2}$ and $K_{3}$

\begin{tabular}{|c|c|c|c|}
\hline $\begin{array}{c}\text { Thermodynamic } \\
\text { Quantities }\end{array}$ & $\begin{array}{c}\text { Values from } \\
\mathbf{K}_{\mathbf{1}}\end{array}$ & $\begin{array}{c}\text { Values from } \\
\mathbf{K}_{\mathbf{2}}\end{array}$ & $\begin{array}{c}\text { Values from } \\
\mathbf{K}_{\mathbf{3}}\end{array}$ \\
\hline \hline$\Delta \mathrm{H}\left(\mathrm{kJ} \mathrm{mol}^{-1}\right)$ & $50.5 \pm 2.5$ & $-73.8 \pm 3.6$ & $47.6 \pm 2.3$ \\
\hline$\Delta \mathrm{S}\left(\mathrm{JK}^{-1} \mathrm{~mol}^{-1}\right)$ & $156 \pm 7$ & $-324 \pm 16$ & $225 \pm 11$ \\
\hline$\Delta \mathrm{G}\left(\mathrm{kJ} \mathrm{mol}^{-1}\right)$ & $3.5 \pm 0.1$ & $24.0 \pm 1.1$ & $-19.7 \pm 0.9$ \\
\hline
\end{tabular}

Here $\mathrm{k}_{\mathrm{T}}$ is the observed pseudo first-order rate constant in the presence of Os(VIII) catalyst ; $\mathrm{k}_{\mathrm{U}}$, the pseudo first-order rate constant for the uncatalysed; $\mathrm{K}_{\mathrm{C}}$, the catalytic constant and ' $x$ ' the order of the reaction with respect to Os(VIII). In the present investigations; $\mathrm{x}$ values for the standard run were found to be unity for $\mathrm{Os}(\mathrm{VIII})$. Then the value of $\mathrm{K}_{\mathrm{C}}$ is calculated using the equation,

$\mathrm{K}_{\mathrm{C}}=\frac{\mathrm{k}_{\mathrm{T}}-\mathrm{k}_{\mathrm{U}}}{[\mathrm{Os}(\mathrm{VIII})]}=\frac{\mathrm{k}_{\mathrm{C}}}{[\mathrm{Os}(\mathrm{VIII})]}$ (where, $\mathrm{k}_{\mathrm{T}}-\mathrm{k}_{\mathrm{U}}=\mathrm{k}_{\mathrm{C}}$ )

The values of $\mathrm{K}_{\mathrm{C}} \times 10^{-2}$ were obtained as 1.4, 2.1, 2.5 and 4.6 at $293,298,303$ and $313 \mathrm{~K}$ temperatures respectively. Further, plots of $\log \mathrm{K}_{\mathrm{C}} v s 1 / \mathrm{T}$ were linear and the values of energy of activation and other activation parameters with reference to catalyst were computed as $\mathrm{Ea}\left(\mathrm{kJ} \mathrm{mol}^{-1}\right)=43.6$, $\Delta \mathrm{H}^{\#}\left(\mathrm{~kJ} \mathrm{~mol}^{-1}\right)=41.1, \Delta \mathrm{S}^{\#}\left(\mathrm{JK}^{-1} \mathrm{~mol}^{-1}\right)=-62.3, \Delta \mathrm{G}^{\#}=59.7$ and $\log \mathrm{A}=9.96$.

\section{DISCUSSION}

The powerful and versatile nature of two electron-oxidant $\mathrm{Ag}$ (III) has led to its use for oxidation of various organic and inorganic substrates. $\mathrm{Ag}(\mathrm{OH})_{4}{ }^{-}$, diperiodatoargentate(III) and ethylenebis (biguanide), (EBS), silver(III) are among those $\mathrm{Ag}(\mathrm{III})$ species which have drawn maximum attention due to their relative stability [17]. The stability of $\mathrm{Ag}(\mathrm{OH})_{4}{ }^{-}$is very sensitive towards traces of dissolved oxygen and other impurities in the reaction medium, therefore it had not drawn much attention. However, the other two forms of $\mathrm{Ag}$ (III) $[3,4,18]$ are considerably more stable; DPA is used in highly alkaline medium and EBS is used in highly acidic medium.

A literature survey [13] reveals that the water soluble diperiodatoargentate(III) (DPA) has a formula $\left[\mathrm{Ag}\left(\mathrm{IO}_{6}\right)_{2}\right]^{7-}$ with $\mathrm{dsp}^{2}$ configuration of square planar structure, similar to a diperiodatocopper(III) complex with two bidentate ligands, periodate to form a planar molecule. When the same molecule is used in alkaline medium, it is unlikely to exist as $\left[\mathrm{Ag}\left(\mathrm{IO}_{6}\right)_{2}\right]^{7_{-}}$as a periodate is known to be in various protonated forms $[19,20]$ depending on the $\mathrm{pH}$ of the solution as given in following multiple equilibria (3)-(5).

$$
\begin{aligned}
& \mathrm{H}_{5} \mathrm{IO}_{6} \rightleftharpoons \mathrm{H}_{4} \mathrm{IO}_{6}{ }^{-}+\mathrm{H}^{+} \mathrm{K}_{1}=5.1 \times 10^{-4} \\
& \mathrm{H}_{4} \mathrm{IO}_{6}{ }^{-} \rightleftharpoons \mathrm{H}_{3} \mathrm{IO}_{6}{ }^{2-}+\mathrm{H}^{+} \mathrm{K}_{2}=4.9 \times 10^{-9} \\
& \mathrm{H}_{3} \mathrm{IO}_{6}{ }^{2-} \rightleftharpoons \mathrm{H}_{2} \mathrm{IO}_{6}{ }^{3-}+\mathrm{H}^{+} \mathrm{K}_{3}=2.5 \times 10^{-12}
\end{aligned}
$$

Periodic acid $\left(\mathrm{H}_{5} \mathrm{IO}_{6}\right)$ exists in acid medium and also as $\mathrm{H}_{4} \mathrm{IO}_{6}{ }^{-}$at $\mathrm{pH}$ 7. Thus, under the present alkaline conditions, the main species are expected to be $\mathrm{H}_{3} \mathrm{IO}_{6}{ }^{2-}$ and $\mathrm{H}_{2} \mathrm{IO}_{6}{ }^{3-}$. At higher concentrations, periodate also tends to dimerise [1]. On the contrary, in the literature [3] proposed the DPA as $\left[\mathrm{Ag}(\mathrm{HL})_{2}\right]^{x-}$ in which " $\mathrm{L}$ " is a periodate with an uncertain number of protons and " $\mathrm{HL}$ " is a protonated periodate of uncertain number of protons. This can be ruled out by considering the alternative form $[19,20]$ of $\mathrm{IO}_{4}{ }^{-}$at $\mathrm{pH}>7$ which is in the form $\mathrm{H}_{3} \mathrm{IO}_{6}{ }^{2-}$ or $\mathrm{H}_{2} \mathrm{IO}_{6}{ }^{3-}$. Hence, DPA could exist as $\left[\mathrm{Ag}\left(\mathrm{H}_{3} \mathrm{IO}_{6}\right)_{2}\right]^{-}$or $\left[\mathrm{Ag}\left(\mathrm{H}_{2} \mathrm{IO}_{6}\right)_{2}\right]^{3-}$ in alkaline medium. Therefore, under the present condition, diperiodatoargentate(III), may be depicted as $\left[\mathrm{Ag}\left(\mathrm{H}_{3} \mathrm{IO}_{6}\right)_{2}\right]^{-}$. The similar speciation of periodate in alkali was proposed [21,22] for diperiodatonickelate (IV).

Os(VIII) is known to form different complexes at different $\mathrm{OH}^{-}[23]$ concentrations $\left[\mathrm{OsO}_{4}(\mathrm{OH})_{2}\right]^{2-}$ and $\left[\mathrm{OsO}_{5}(\mathrm{OH})\right]^{3-}$. At higher concentration of $\mathrm{OH}^{-},\left[\mathrm{OsO}_{5}(\mathrm{OH})\right]^{3-}$ is significant. At lower concentrations of as employed in present study, and since the rate of oxidation increased with increase in $\left[\mathrm{OH}^{-}\right]$, it is reasonable that $\left[\mathrm{OsO}_{4}(\mathrm{OH})_{2}\right]^{2-}$ was operative and its formation is important in the reaction. To explain the observed orders the following Scheme $\mathbf{2}$ is proposed for osmium(VIII) catalysed reaction. 
In the prior equilibrium step 1 , the $\left[\mathrm{OH}^{-}\right]$deprotonates the DPA to give a deprotonated diperiodatoargentate(III); in the second step, displacement of a ligand, periodate takes place to give free periodate which is evidenced by decrease in the rate with increase in [periodate] (Table 1). It may be expected that a lower $\mathrm{Ag}(\mathrm{III})$ periodate species such as MPA is more important in the reaction than the DPA. In the pre-rate determining stage, the Os(VIII) species combines with a molecule of anionic species of DFS to give an intermediate complex (C), which further reacts with one molecule of MPA which decomposes in a slow step to give the free radical derived from DFS, Ag(II) species and regeneration of catalyst, osmium(VIII). This free radical of DFS combines with $\mathrm{Ag}$ (II) species in a fast step to give an [2-(2, 6-dichloro-phenylamino)-phenyl]-methanol. Thus, all these results indicate a mechanism of the type as in Scheme 2.

The probable structure of complex (C) is given in Scheme 3.

Spectroscopic evidence for the complex formation between Os(VIII) and DFS was obtained from UV-vis spectra of DFS $\left(5.0 \times 10^{-4}\right)$, Os(VIII) $\left(8.0 \times 10^{-6}\right),\left[\mathrm{OH}^{-}\right]=0.5\left(\mathrm{~mol} \mathrm{dm}^{-3}\right)$ and mixture of both. A bathochromic shift of about $6 \mathrm{~nm}$ from 242 to $248 \mathrm{~nm}$ in the spectra of Os(VIII) and hyperchromicity at 248 $\mathrm{nm}$ was observed. The Michaelis-Menten plot also proved the complex formation between Os(VIII) and DFS, which explains the less than unit order dependence on DFS. Such type of complex between substrate and catalyst has been observed in other studies [24]. A unique isobestic point, observed at 410nm, indicates the presence of single complex. Scheme 2 leads to the following rate law (6).

$$
\begin{aligned}
& \text { Rate }=\frac{-\mathrm{d}[\mathrm{DPA}]}{\mathrm{dt}} \\
& =\frac{\mathrm{kK}_{1} \mathrm{~K}_{2} \mathrm{~K}_{3}[\mathrm{DPA}][\mathrm{DFS}][\mathrm{OH}-][\mathrm{Os}(\mathrm{VIII})]}{\left[\mathrm{H}_{3} \mathrm{IO}_{6}{ }^{2-}\right]+\mathrm{K}_{1}\left[\mathrm{OH}^{-}\right]\left[\mathrm{H}_{3} \mathrm{IO}_{6}{ }^{2-}\right]+\mathrm{K}_{1} \mathrm{~K}_{2}\left[\mathrm{OH}^{-}\right]+\mathrm{K}_{3}[\mathrm{DFS}]\left[\mathrm{H}_{3} \mathrm{IO}_{6}{ }^{2-}\right]} \\
& +\mathrm{K}_{1} \mathrm{~K}_{3}[\mathrm{DFS}][\mathrm{OH}-]\left[\mathrm{H}_{3} \mathrm{IO}_{6}{ }^{2-}\right]+\mathrm{K}_{1} \mathrm{~K}_{2} \mathrm{~K}_{3}[\mathrm{OH}-][\mathrm{DFS}]
\end{aligned}
$$

The terms $\mathrm{K}_{3}\left[\mathrm{H}_{3} \mathrm{IO}_{6}{ }^{2-}\right][\mathrm{DFS}]$ and $\mathrm{K}_{1} \mathrm{~K}_{3}[\mathrm{DFS}]\left[\mathrm{OH}^{-}\right]\left[\mathrm{H}_{3} \mathrm{IO}_{6}{ }^{2-}\right]$ of denominator of eq. (6) can be neglected in the view of low concentrations of DFS and periodate used in study.

Therefore, eq. (6) becomes

$$
\begin{aligned}
& \frac{\text { Rate }}{[\mathrm{DPA}]}=\mathrm{k}_{\mathrm{C}}=\mathrm{k}_{\mathrm{T}}-\mathrm{k}_{\mathrm{U}} \\
& =\frac{\mathrm{kK}_{1} \mathrm{~K}_{2} \mathrm{~K}_{3}[\mathrm{DFS}][\mathrm{OH}-][\mathrm{Os}(\mathrm{VIII})]}{\left[\mathrm{H}_{3} \mathrm{O}_{6}{ }^{2-}\right]+\mathrm{K}_{1}[\mathrm{OH}-]\left[\mathrm{H}_{3} \mathrm{IO}_{6}{ }^{2-}\right]+\mathrm{K}_{1} \mathrm{~K}_{2}[\mathrm{OH}-]+\mathrm{K}_{1} \mathrm{~K}_{2} \mathrm{~K}_{3}[\mathrm{DFS}][\mathrm{OH}-]}
\end{aligned}
$$

which explains all the observed kinetic orders of different species. The rate law (7) can be rearranged to eq. (8), which is suitable for verification.

$$
\frac{[\mathrm{Os}(\mathrm{VIII})]}{\mathrm{k}_{\mathrm{C}}}=\frac{\left[\mathrm{H}_{3} \mathrm{IO}_{6}{ }^{2 \cdot}\right]}{\mathrm{kK}_{1} \mathrm{~K}_{2} \mathrm{~K}_{3}[\mathrm{DFS}][\mathrm{OH} \cdot]}+\frac{\left[\mathrm{H}_{3} \mathrm{IO}_{6}{ }^{2 \cdot}\right]}{\mathrm{kK}_{2} \mathrm{~K}_{3}[\mathrm{DFS}]}+\frac{1}{\mathrm{kK}_{3}[\mathrm{DFS}]}+\frac{1}{\mathrm{k}}
$$

According to equation (8), plots of $[\mathrm{Os}(\mathrm{VIII})] / \mathrm{k}_{\mathrm{C}} v s 1 /\left[\mathrm{OH}^{-}\right]$, $[\mathrm{Os}(\mathrm{VIII})] / \mathrm{k}_{\mathrm{C}}$ vs $1 /[\mathrm{DFS}]$ and $[\mathrm{Os}(\mathrm{VIII})] / \mathrm{k}_{\mathrm{C}}$ vs $\left[\mathrm{H}_{3} \mathrm{IO}_{6}{ }^{2-}\right]$ were linear as in Fig. (5). From the slopes and intercepts of such plots, the reaction constants, $\mathrm{K}_{1}, \mathrm{~K}_{2}, \mathrm{~K}_{3}$ and $\mathrm{k}$ were calculated as $(0.20 \pm 0.008) \mathrm{dm}^{3} \mathrm{~mol}^{-1},(1.03 \pm 0.05) \times 10^{-4} \mathrm{~mol} \mathrm{dm}^{-3},(2.60 \pm$ $0.12) \times 10^{3} \mathrm{dm}^{3} \mathrm{~mol}^{-1}$ and $(5.28 \pm 0.12) \times 10^{2} \mathrm{dm}^{3} \mathrm{~mol}^{-1} \mathrm{~s}^{-1}$ respectively. The values of $K_{1}$ and $K_{2}$ obtained were in good agreement with previously reported values [24]. These constants were used to calculate the rate constants and compared with experimental $\mathrm{k}_{\mathrm{C}}$ values and found to be in reasonable agreement with each other, which fortifies the Scheme 2. The equilibrium constant $\mathrm{K}_{1}$ is far greater than $\mathrm{K}_{2}$ which may be attributed to the greater tendency of DPA to under go deprotonation compared to the formation of hydrolysed species in alkaline medium.

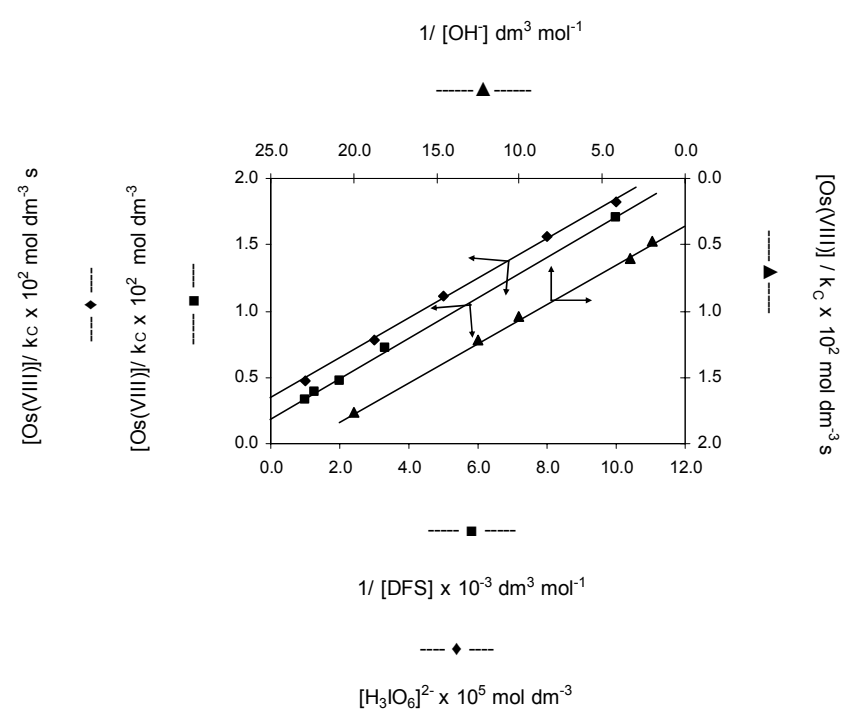

Fig. (5). Plot of verification of rate law Eq. (7) in the form of Eq.(8) of Os(VIII) catalysed oxidation of diclofenac sodium by diperiodatoargantate (III) in aqueous alkaline medium at $25^{\circ} \mathrm{C}$.

The thermodynamic quantities for the first, second and third equilibrium steps of Scheme $\mathbf{2}$ can be evaluated as follows. The DFS, $\mathrm{OH}^{-}$and $\mathrm{IO}_{4}^{-}$concentrations (Table 1) were varied at different temperatures. The plots of $[\mathrm{Os}(\mathrm{VIII})] / \mathrm{k}_{\mathrm{C}} v s 1 /[\mathrm{DFS}](\mathrm{r}$ $\geq 0.999),[\mathrm{Os}(\mathrm{VIII})] / \mathrm{k}_{\mathrm{C}}$ vs $\left[\mathrm{H}_{3} \mathrm{IO}_{6}{ }^{2-}\right](\mathrm{r} \geq 0.999),[\mathrm{Os}(\mathrm{VIII})] / \mathrm{k}_{\mathrm{C}} v s$ $1 /\left[\mathrm{OH}^{-}\right](\mathrm{r} \geq 0.999)$ were linear as shown in Fig. (5). From the slopes and intercepts, the values of $\mathrm{K}_{1}$ were calculated at different temperatures. A vant Hoff's plots were made for variation of $\mathrm{K}_{1}$ with temperature [i.e., $\log \mathrm{K}_{1} v s \quad 1 / \mathrm{T}(\mathrm{r} \geq$ 0.9958)] and the values of enthalpy of reaction $\Delta \mathrm{H}$, entropy of reaction $\Delta \mathrm{S}$ and free energy of reaction $\Delta \mathrm{G}$, were calculated. These values are given in Table 2. A comparison of $\Delta \mathrm{H}$ value $(50.5 \pm 2.5)$ from $\mathrm{K}_{1}$ with that of $\Delta \mathrm{H}^{\#}(24.2 \pm 1.2)$ of rate limiting step supports that the first step of Scheme $\mathbf{2}$ is fairly slow since it involves high activation energy [25]. In the same manner, $\mathrm{K}_{2}$ and $\mathrm{K}_{3}$ values were calculated at different temperatures and the corresponding values of thermodynamic quantities are given in Table $\mathbf{2}$.

The effect of ionic strength and dielectric constant on the rate of the reaction qualitatively explains the involvement of a neutral species as given in Scheme 2.

The values of $\Delta \mathrm{H}^{\#}$ and $\Delta \mathrm{S}^{\#}$ were both favourable for electron transfer processes. The favourable enthalpy was due to release of energy on solutions changes in the transition state. The negative value of $\Delta \mathrm{S}^{\#}$ indicates that the intermediate complex (C) is more ordered than the reactants [26]. The observed modest enthalpy of activation and a higher rate constant for the slow step indicates that the oxidation 
presumably occurs via an inner-sphere mechanism. This conclusion is supported by early observations [27]. The activation parameters evaluated for the catalysed and uncatalysed reaction explain the catalytic effect on the reaction. The catalyst Os(VIII) form the complex (C) with substrate which enhances the reducing property of the substrate than that without catalyst. Further, the catalyst Os(VIII) modifies the reaction path by lowering the energy of activation.

\section{CONCLUSION}

The Os(VIII) catalysed oxidation of DFS by diperiodatoargentate(III) was studied. Oxidation products were identified. Among the various species of $\mathrm{Ag}(\mathrm{III})$ in alkaline medium, in earlier reports the diperiodatoargentate(III) was the active species, whereas monoperiodatoargentate(III) itself is considered to be active species for the title reaction. Active species of $\mathrm{Os}(\mathrm{VIII})$ is $\left[\mathrm{OsO}_{4}(\mathrm{OH})_{2}\right]^{2-}$. Activation parameters were evaluated. Catalytic constants and the activation parameters with reference to catalyst were also computed.

\section{ACKNOWLEDGEMENT}

One of the authors (R. H. P) thanks UGC, New Delhi for the award of meritorious fellowship.

\section{APPENDIX}

$$
\begin{gathered}
\text { Rate }=\frac{-\mathrm{d}[\mathrm{DPA}]}{\mathrm{dt}[\mathrm{DPA}]_{\mathrm{T}}=[\mathrm{DPA}]_{\mathrm{f}}+[\mathrm{Ag}]^{2-}+[\mathrm{Ag}]}=\frac{\mathrm{k} \mathrm{K}_{1} \mathrm{~K}_{2} \mathrm{~K}_{3}[\mathrm{DFS}]_{\mathrm{f}}[\mathrm{Os}(\mathrm{VIII})]_{\mathrm{f}}[\mathrm{DPA}]_{\mathrm{f}}\left[\mathrm{OH}^{-}\right]_{\mathrm{f}}}{\left[\mathrm{H}_{3} \mathrm{IO}_{6}{ }^{2-}\right]} \\
{[\mathrm{DPA}]_{\mathrm{T}}=[\mathrm{DPA}]_{\mathrm{f}}\left\{1+\mathrm{K}_{1}[\mathrm{OH}]+\frac{\mathrm{K}_{1} \mathrm{~K}_{2}\left[\mathrm{OH}^{-}\right]}{\left[\mathrm{H}_{3} \mathrm{IO}_{6}{ }^{2-}\right]}\right\}} \\
{[\mathrm{DPA}]_{\mathrm{f}}=\frac{[\mathrm{DPA}]_{\mathrm{T}}\left[\mathrm{H}_{3} \mathrm{IO}_{6}{ }^{2-}\right]}{\left[\mathrm{H}_{3} \mathrm{IO}_{6}{ }^{2-}\right]+\mathrm{K}_{1}\left[\mathrm{OH}^{-}\right]\left[\mathrm{H}_{3} \mathrm{IO}_{6}{ }^{2-}\right]+\mathrm{K}_{1} \mathrm{~K}_{2}\left[\mathrm{OH}^{-}\right]}}
\end{gathered}
$$

where $[\mathrm{Ag}]^{2-}=\left[\mathrm{Ag}\left(\mathrm{H}_{2} \mathrm{IO}_{6}\right)\left(\mathrm{H}_{3} \mathrm{IO}_{6}\right)\right]^{2-},[\mathrm{Ag}]=\left[\mathrm{Ag}\left(\mathrm{H}_{2} \mathrm{IO}_{6}\right)\left(\mathrm{H}_{2} \mathrm{O}\right)_{2}\right]$ subscripts $\mathrm{T}$ and $\mathrm{f}$ stand for total and free concentrations respectively.

Similarly,

$$
\begin{aligned}
{[\mathrm{Os}(\mathrm{VIII})]_{\mathrm{T}} } & =[\mathrm{Os}(\mathrm{VIII})]_{\mathrm{f}}+[\mathrm{C}]=[\mathrm{Os}(\mathrm{VIII})]_{\mathrm{f}}\left\{1+\mathrm{K}_{3}[\mathrm{DFS}]\right\} \\
{[\mathrm{Os}(\mathrm{VIII})]_{\mathrm{f}} } & =\frac{[\mathrm{Os}(\mathrm{VIII})]_{\mathrm{T}}}{1+\mathrm{K}_{3}[\mathrm{DFS}]} \quad(\mathrm{III}) \quad[\mathrm{DFS}]_{\mathrm{f}}=\frac{[\mathrm{DFS}]_{\mathrm{T}}}{1+\mathrm{K}_{3}[\mathrm{Os}(\mathrm{VIII})]}
\end{aligned}
$$

In eq. (IV) low concentrations of osmium(VIII) used, so the term $1+\mathrm{K}_{3}[\mathrm{Os}(\mathrm{VIII})]$ is neglected. Therefore,

$$
[\mathrm{DFS}]_{\mathrm{f}}=[\mathrm{DFS}]_{\mathrm{T}}(\mathrm{V}) \quad \text { Similarly, } \quad\left[\mathrm{OH}^{-}\right]_{\mathrm{f}}=\left[\mathrm{OH}^{-}\right]_{\mathrm{T}}
$$

Substituting eq. II, III, V and VI in eq. I, we get

$$
\begin{aligned}
\frac{-\mathrm{d}[\mathrm{DPA}]}{\mathrm{dt}}= & \frac{\mathrm{k} \mathrm{K}_{1} \mathrm{~K}_{2} \mathrm{~K}_{3}[\mathrm{DPA}][\mathrm{DFS}][\mathrm{OH}-][\mathrm{Os}(\mathrm{VIII})]}{\left[\mathrm{H}_{3} \mathrm{IO}_{6}{ }^{2-}\right]+\mathrm{K}_{1}\left[\mathrm{OH}^{-}\right]\left[\mathrm{H}_{3} \mathrm{IO}_{6}{ }^{2-}\right]+\mathrm{K}_{1} \mathrm{~K}_{2}\left[\mathrm{OH}^{-}\right]+\mathrm{K}_{3}[\mathrm{DFS}]\left[\mathrm{H}_{3} \mathrm{IO}_{6}{ }^{2-}\right]} \\
& +\mathrm{K}_{1} \mathrm{~K}_{3}[\mathrm{DFS}]\left[\mathrm{OH}{ }^{-}\right]\left[\mathrm{H}_{3} \mathrm{IO}_{6}{ }^{2-}\right]+\mathrm{K}_{1} \mathrm{~K}_{2} \mathrm{~K}_{3}\left[\mathrm{OH}^{-}\right][\mathrm{DFS}]
\end{aligned}
$$




\section{REFERENCES}

[1] Sethuram, B. Some aspects of Electron - Transfer Reactions Involving Organic Molecules, Allied Publishers (P) Ltd: New Delhi, 2003, pp. 151.

[2] Jaiswal, P. K.; Yadava, K. L. Silver(III) as an oxidative titrant: Determination of some sugars, carboxylic acids and inorganic ions. Talanta, 1970, 17(3), 236-238.

[3] Jayaprakash Rao, P.; Sethuram, B.; Navaneeth Rao, T. Kinetics of oxidative deamination of some amino acids by diperiodatoargentate(III) in alkaline medium. React. Kinet. Cat. Lett., 1985, 29(1), 289-296.

[4] Kumar, A.; Kumar, P.; Ramamurthy, P. Kinetics of oxidation of glysine and related substrates by diperiodatoargentate(III). Polyhedron, 1999, 18(6), 773-780.

[5] Iliescu, T.; Baia, M.; Miclaus, V. A Raman spectroscopic study of the diclofenac sodium- $\beta$-cyclodextrin interaction. Eur. J. Pharm. Sci., 2004, 22(5), 487-495.

[6] Gostick, N.; James, I. G.; Khong, T. K.; Roy, P.; Shepherd, P. R.; Miller, A. J. Controlled-release indomethacin and sustained-release diclofenac sodium in the treatment of osteoarthritis: A comparative controlled clinical trial in general practice. Curr. Med. Res. Opin., 1990, 12(3), 135-142.

[7] Das, A. K. Kinetic and mechanistic aspects of metal ion catalysts in cerium(IV) oxidation. Coord. Chem. Rev., 2001, 213(1), 307-325.

[8] Agarwal, M. C.; Upadhyay, S. K. Osmium(VIII) catalyst in some redox reactions. J. Sci. Ind. Res., 1983, 42, 508-517.

[9] Veera somaiah, P.; Bal Reddy, K.; Sethuram, B.; Nananeeth Rao, $\mathrm{T}$. Role of osmium tetroxide in oxidation of 2-propanol presence and absence of different one and two-equivalent oxidants in aqueous alkaline medium. Indian J. Chem., 1987, 26A(5), 402-406.

[10] Naik, P. N.; Chimatadar, S. A.; Nandibewoor, S. T. Oxidation of dicloefenac sodium by diperiodatoargentate(III) in aqueous alkaline medium and its determination in urine and blood by kinetic methods. Int. J. Chem. Kinet., 2009, in press.

[11] Saxena, O. C. New titrimetric microdetermination of osmium. Microchem. J., 1967, 12(4), 609-611.

[12] Panigrahi, G. P.; Misro, P. K. Kinetics and mechanism of oxidation of osmium(VIII) catalysed oxidation of unsaturated acids by sodium periodate. Indian. J. Chem., 1978, 16A(3), 201-204.

[13] Cohen, G.L.; Atkinson, G. The chemistry of argentic oxide. The formation of a silver(III) complex with periodate in basic solution. Inorg. Chem., 1964, 3(12), 1741-1743.

[14] Jeffery, G. H.; Bassett, J.; Mendham, J.; Denney, R. C. Vogel's Textbook of Quantitative Chemical Analysis, $5^{\text {th }}$ ed.; Longmans Singapore Publishers Pte Ltd: Singapore, 1996, p. 467.
[15] Jagdeesh R. V.; Puttaswamy. Ru(III), Os(VIII), Pd(II) and Pt(IV) catalysed oxidation of glycyl-glycine by sodium N-chloro-ptoluenesulfonamide: Comparative mechanistic aspects and kinetic modeling. J. Phy. Org. Chem., 2008, 21, 844-858.

[16] Moelwyn-Hughes, E. A. Kinetics of Reaction in Solutions, Oxford University Press: London, 1947, pp. 297-299.

[17] Krischenbaum, L. J.; Mrozowski, L. Kinetics of silver(III) decomposition in diluted acid. Inorg. Chem., 1978, 17(2), 37183719.

[18] Banerjee, R.; Das, K.; Das, A.; Dasgupta, S. Kinetics of silver(I)catalyzed oxidation of formic acid by the (Ethylenebis(biguanidine)) silver(III) cation in acid perchlorate media. Inorg. Chem., 1989, 28(3), 585-588.

[19] Crouthamel, C. E.; Meek, H. V.; Martin, D. S.; Banks, C. V. Spectrophotometric studies of diluted aqueous periodate solutions. J. Am. Chem. Soc., 1949, 71(9), 3031-3035.

[20] Crouthamel, C. E.; Hayes, A. M.; Martin, D. S. Ionization and hydration equilibria of periodic acid. J. Am. Chem. Soc., 1951, 73(1), 82-87.

[21] Bhattacharya, S.; Saha, B.; Datta, A.; Banerjee, P. Electron transfer reactions of nickel(III) and nickel(IV) complexes. Coord. Chem. Rev., 1998, 170(1), 47-74.

[22] Haines, R. I.; McAuley, A. Synthesis and reactions of nickel(III) complexes. Coord. Chem. Rev., 1981, 39(1-2), 77-119.

[23] Kamble, D. L.; Nandibewoor, S. T. Osmium(VIII)/Ruthenium(III) catalysis of periodate oxidation of acetaldehyde in aqueous alkaline medium. J. Phy. Org. Chem., 1998, 11(3), 171-176.

[24] Hiremath, C. V.; Kiran, T. S.; Nandibewoor, S. T. $\mathrm{Os}(\mathrm{VIII}) / \mathrm{Ru}(\mathrm{VIII})$ catalysed oxidation of aspirin drug by a new oxidant, diperiodatoargentate(III) in aqueous alkaline medium: A comparative kinetic study. J. Mol. Catal. A., 2006, 248(1-2), 163174.

[25] Rangappa, K. S.; Raghavendra, M. P.; Mahadevappa, D. S.; Channegouda, D. Sodium N-chlorobenzonesulfonamide as a selective oxidant for hexasomines in alkaline medium: A kinetic and mechanistic study. J. Org. Chem., 1998, 63(3), 531-536.

[26] Weissberger, A. In Investigation of Rates and Mechanism of Reactions in Techniques of Chemistry, $4^{\text {th }}$ ed., Lewis, E.S. Ed.; Wiley: New York, 1974, pp. 421.

[27] Farokhi, S. A.; Nandibewoor, S.T. Kinetic, mechanistic and spectral studies for the oxidation of sulfanilic acid by hexacyanoferrate(III). Tetrahedron, 2003, 59(38), 7595-7602.

Received: May 10, 2009

Revised: June 10, 2009

Accepted: June 10, 2009

(C) Patil et al.; Licensee Bentham Open.

This is an open access article licensed under the terms of the Creative Commons Attribution Non-Commercial License (http://creativecommons.org/licenses/by-nc/ $3.0 /$ ) which permits unrestricted, non-commercial use, distribution and reproduction in any medium, provided the work is properly cited. 